\title{
CHAPTER 69
}

\section{A COMPARISON OF FLUVIAL AND COASTAL SIMILITUDE}

By Bernard Le Mehaute, D Sc

Vice-President, Tetra Tech, Inc

Pasadena, Calıfornia

\begin{abstract}
A comparison of the conditions of similitude for movable bed scale models of rivers and estuaries on one hand, and beaches and shorelines on the other hand, is presented It is demonstrated that despite the fact that the knowledge in sediment transport by wave action is less advanced than in the case of steady current, the conditions of similitude for beaches are less stringent than for rivers In particular, the effect of relative roughness is comparatively unimportant in the case of beaches, while the necessity of similitude of head loss imposes an imperative condition in the case of scale models of rivers An introduction to a natural law of distortion for beaches is presented in analogy with the Lacey condition for rivers
\end{abstract}

\section{INTRODUCTION}

Belief in movable bed scale model technology is somewhat mystical--God's existence can be proven by $\log 1 \mathrm{c}$, while as many reasons can be proposed for proving the opposite This belief is not a matter of logic--it is a matter of faith Similarly, agnostic specialists in sediment transport can easily find many reasons why similitude of movable bed scale models is not possible On the other hand, hydraulic engineers believe in movable bed scale model technology as a tool for solving practical problems and guiding their intuition Sometimes this belief or disbelief is completely irrational One finds the scientist who does not want to admit that this tool could be of practical value and one also finds the engineer whose faith in his scale model fringes on the rim of superstition, while he should know its limit of validity The analogy can be further prolonged by considering that different scale model practices and technology prevailing in different hydraulic laboratories correspond to slightly different religions But the road to salvation is not unique--despite some disagreement between laboratories on what should be done, none of these methods is "completely wrong" One can only discuss what could be the most universal approach-- the better approach actually being the one which is the best mastered by individual experimenters

A detailed investigation of what can and cannot be done in movable bed scale models dealing with coastal structures has been presented in a previous report (Fan and Le Mehauté, 1969) This presentation will be limited to some reflections which may not necessarily be original, but which are felt pertinent to this convention, which assembles agnostics as well as believers in movable bed scale models One would like to clearly establish that the chance for success of a movable bed scale model dealing with shoreline processes is much higher than a movable bed model of fluvial hydraulics Subsequently, the first kind of model will require less knowledge in the law of sediment transport and less astuteness on the part of the experimenter than the second kind

The reasons which make a coastal model more reliable than a river model are

a) A less imperative choice of the condition of similitude This is discussed at length in the following In general, coastal models do not 
require any condition on bottom roughness, while the necessity of reproducing head loss in similitude in fluvial models imposes an additional condition upon the size of the model material to be used

b) A wider cholce of criteria of similitude in the case of a coastal model One can always satisfactorily reproduce an observed shoreline evolution by adjusting wave height, period, direction, duration, or intensity of tidal current (However, similitude of sand deposit taking place in a diffraction area may be subjected to scale effects)

In fluvial hydraulics, the choice of criteria is limited to typical flood histograms and required fineness of topography (Secondary meandering effect may not need to be reproduced in similitude)

c) The third reason for making coastal models more successful is related to the problem of hydraulic instability A river flowing in its own alluvium is fundamentally unstable in the sense that if there is erosion, more wate $r$ will flow, and, consequently, more erosion will follow The study of a meandering iıver on a scale model is only possible if the banks are fixed A meandering process can be reproduced on a scale model only if it obeys a well defined cycle, such as the Seine estuary

In coastal processes if one excepts cusps and rip currents on long, straight beaches, the flow pattexn is generally well determined by an imposed bottom topography Short coastal engineering scale models always deal with well defined topography and man-made works, such as harbor entrances Consequently, there is a general tendency towards a stable state a dune tends to be flattened out and a channel tends to be filled

d) Finally, the last reason for the success of coastal engineering models is due to the fact that beaches are generally made of relatively uniform noncohesive material, while rivers may present a much wider size distribution of material and have cohesive characteristics The law of similitude for cohesive material cannot be established until more is known about the sediment transport of cohesive material

\section{PRELIMINAR Y REMARKS}

Prior to entering this subject, it is pertinent to briefly recall some of the fundamental principles governing movable bed scale model technology

1) Quotıng L F Vernon-Harcourt, who contınued the work of Reynolds

"If I succeed in demonstrating with the model that the originally existing conditions can be reproduced typically, and if, moreover, by placing regulating works in the model, the same changes can be reproduced that were brought about by the training works actually built, then I am sure that I can take the third and most important step, namely, of investigating, with every promise of success, the probable effect of the projects that have been proposed "

This principle has been the basic guideline ever since

2) A movable bed scale model must fulfill the following conditions

a) It must be exact 1 e, it must reproduce with exactness the natural phenomenon under study 
b) It must be consistent 2 e it must always give the same results under the same conditions

c) It must be sensitive--or more exactly, its sensitivity has to be imposed by the fineness of the topography which needs to be reproduced for the phenomenon under investigation Secondary meandering flow, small benches, and at the limit ripples, will, of course, not need to be reproduced in the scale model

d) It must be economical, of reasonable size, and completed within a reasonable time interval

3) In a movable bed scale model, the basic similitude requirement is the reproduction of bottom evolution observed in the field even if it is not achieved through exact similitude of water motion (the way in which water motion is simulated must be logical so that it can be extended to future conditions) Reproducibility of test results under the same conditions is a general requirement for all experimental studies This requirement of the model also implies stability under random disturbances An unstable phenomenon cannot be studied adequately in a movable bed model

"For example, it would be illusive to study the stability of a river flowing in its own alluvium on a scale model because a simple bush or a local soil a little more cohesive can definitely guide a meander in a way different from the model result Such studies embody by their very nature a risk of complete faslure " (Le Méhauté, 1962 )

4) It is important to distinguish between conditions of similitude and criteria of similitude The conditions of similitude are an ensemble of formulas deduced from the physical laws governing the phenomena under investigation e $g$, the similitude condition governing sediment transport is obtained by an analysis of the mechanics of sediment transport They have an absolute definition which cannot be changed unless an improvement in the knowledge of the physical law $1 \mathrm{~s}$ obtained They are not chosen by the experimenter but are imposed on him Unfortunately, it is known that in the field of sediment transport, many phenomena still remain to be analyzed or clarified Thus, the conditions of similitude are not as well defined as they should be A choice of what is important will have to be based again on the knowledge of these laws obtained by "1nspectional analysis"

In performing a model study, an experimenter must specify certain criteria such as model wave conditions and fineness of model bottom features The criteria of similitude is a free choice of the experimenter to a very large extent For example, sea states vary from day to day and from hour to hour The experimenter will choose, for the sake of simplicity as well as practical necessity, a characteristic wave condition and will only be able to reproduce simplified storm and swell conditions on the scale model He will choose the wave direction and the wave amplitude and the duration guided by his knowledge of natural conditions In particular, the wave generato $\mathbf{r}$ will generate waves at an angle which corresponds to the dominant direction of storm wave energy Even though he 15 guided by his knowledge of wave statistics, his final choice will be determined by a trial and error method which permits him to reproduce the same bottom evolution as observed in the prototype This faithful reproduction of bottom evolution determines 
the choice of the wave characteristics, rather than the strict conditions of similitude of wave motion

Other criteria of similitude will be to what extent he wants to reproduce the fineness of the bottom topography, a typical tide cycle, the currents and their variations with time, and so on In summary, the criteria of similitude are specified by the experimenter as reasonable approximations for simplification of model operation

5) Movable bed scale models are distorted, 1 e, the vertical scale is different from the horizontal scale Distortion is not an engineering trick for reducing the size of the model and the bottom friction, but is the extrapolation of a natural observed phenomenon The method to obtain a satisfactory scale model is first to obey the law of nature, even though this law may not be fully understood For example, a small river flowing in its own alluvium can be considered a distorted model of a large river This means that the ratio depth to width of the small river is comparatively greater than the relative depth of the larger one The ratios of depths $\mu$ and widths $\lambda$ are approximately related by the law of Lacey $\left(\lambda^{2}=\mu^{3}\right)$, in accordance with the "regime theory" Similarly, a beach in a protected area has a relatively steep slope, while a beach in an exposed area tends to have a more gentle slope (Wregel, 1964) The vertical scale being defined by the ratio of incident wave heights, a protected beach can be considered as a distorted scale model of an exposed beach in both the case of the river and the beach, the cholce of distortion becomes a stringent condition to be respected quantitatively, however, the natural law determined by statistical observation of natural phenomena needs to be modified in the case of a river model due to the fact that scale models generally do not use the same material as the prototypes in order to satisfy other conditions of similitude On the other hand, natural distortion based on the use of sand is compatible with other conditions of similitude in the cases of beaches as will be seen in the following However, the use of sand would rather be discarded as leading to too large a distortion and, subsequently, to large scale effects

6) To the old teaching tradition which consists of presenting a parallel between Froude and Reynolds similitude, I would prefer to make a parallel between what we can call "short model" and "long model" In a short scale model, viscous friction is unimportant as compared to gravity and inertia, therefore, it is governed by Froude similitude Also, energy dissipation may result from a fully turbulent condition, as in the case of a hydraulic jump or a wave breaking on a beach Boundary layer effects in both cases are unimportant The dissipative forces are also proportional to the square of velocity like the inertial forces (A small hydraulic jump is a scale model of a large hydraulic jump under proper depths-discharge relationships) This is the generalized Froude similitude

On the other hand, in a long model, friction has a definite influence on the flow pattern therefore, in addition, a similitude of head loss is required This head loss is a function of the Reynolds number, but is not determined by the so-called Reynolds similitude requiring an equality of Reynolds numbers Therefore, similitude for long models requires, in addition to the Froude similitude, another condition which makes long models more difficult, if not impossible, to handle The model of a smooth concretelined gallery cannot provide a "Froudian" discharge under similar pressure head, since the friction coefficient can only be larger at a smaller Reynolds number (Moody diagram) On the other hand, the head loss in the scale model of a rough (rocky) gallery can be adjusted for the same friction factor insuring the Froude similitude to be satisfied 
The magnitude of long shore currents and location of rip currents may, to some extent, depend upon friction characteristics of the beaches, in which case the study of this phenomena would have to be considered as belonging to the categories of long models, and therefore, may not be studied on scale models Nevertheless, most scale model studies have to deal with short coastal structures(like entrance of harbor), and therefore, the water motion is not too dependent upon the friction coefficients The main dissipative mechanism is due to wave breaking If viscous damping is too significant, as in the case where the wave has to travel a long distance in very shallow water, it just means that the model is not properly designed However, very rarely do we have to be concerned with adjustments of roughness for similitude of energy dissipation, and coastal models can be considered as short models On the other hand, as has been pointed out previously, a similitude of head loss is imperative for models of rivers and estuaries - these are long models Despite this adjustment, vertical velocity distribution being a function of the Reynolds number could never be in similitude

7) This relative advantage of a short model is somewhat balanced by the lack of knowledge of sediment transport by wave action The law of sediment transport in rivers is relatively well understood Therefore, the condition of similitude may be established with more certainty than in the case of beaches Boundary layer characteristics do not vary too much from one place to another While on the other hand, in the case of beaches, the boundary layer characteristics vary from off shore to the upsurge of the wave A cholce has to be made concerning which part of the beach we want to have the best similitude requirements In general, it will be in the breaking zone, where the shearing force at the bottom is quadratic However, it is to be realized that because of this variation of boundary layer characteristics from place to place perpendicular to the beach, a total similitude 1 s impossible

8) In designing a movable bed model, there are four basic unknowns namely, horizontal scale $\lambda$ vertical scale $\mu$, sediment size $\delta$, and sediment specif $1 \mathrm{c}$ weight $\gamma_{s}$, which require at the most four basic equations However, the horizontal scale $1 \mathrm{~s}$ generally determined by economic considerations and available space The three remaining unknowns are relatively well determined in the case of a river, by a well accepted unique set of conditions of similitude as summarized in a following section

In the case of beaches, there is a great controversy concerning which condition of similitude should be imperative This controversy is due on one hand to a lack of knowledge of the law of littoral processes but is also due to the fact that the road to a successful coastal model is not unique As a matter of fact, a thorough analysis of the subject matter may only lead to two conditions which give us a free choice for one of the unknowns These conditions are 1) an equality of ratio of shearing force to relative gravity, the shearing force being quadratic as in the case of a turbulent boundary layer, and 2) a second condition is imposed by the law of dis tortion of beaches (equilıbrium profile of beaches) under different wave actions, which embodies globally many misunderstood phenomena In addition to these two, one can choose somewhat arbitrarily another con. dition, such as a dynamic condition $n_{u} / n_{w}=\lambda / \mu$, where $u$ is a horizontal current, $w$ is the free fall velocity of the particles One would rather choose an equality of boundary layer Reynolds number $R *$ The theoret1cal formulation based on these assumptions is presented in the following section, based on the assumption that the scale for the friction factor is the same as in the case of a fully turbulent flow, as in the surf zone 
This relative freedom is partly due to the lack of understanding of the law of sediment transport under wave action But it is also an indication of one of the reasons why coastal models are generally more successful than fluvial models

9) It is pertinent to point out that since the only requirement of a movable bed model is a reproduction of bottom evolution, it is not necessary that this be achieved through exact similitude of water motion Since the model is distorted, a similitude wave refraction and wave breaking only is being searched as a most satisfying condition, susceptible to producing satisfactory reproduction of long shore current and sediment transport distribution This is achieved by keeping the ratio of wave lengths and wave heights like vertical scale $\mu$ Based upon this condition, the following wave characteristics are preserved in the model a) wave steepness, b) refraction pattern and angle or refraction with bottom contours, c) breaking angle of wave crests with shorelines if the distortion is not too large, and d) breaking depth

Also, the scale for long shore current and mass transport velocities is approximately $\mu \frac{1}{2}$ Therefore, the ratio of scales of wave particle velocity to current velocity is approximately unity

\section{A BRIEF REVIEW OF THE HY DRAULIC PROPERTIES OF SEDIMENTS UNDER}

\section{WAVE ACTION AND CURR ENT}

1) It is first recalled that in the case of water waves, the laminar shear velocity $u_{\not<}\left(\right.$ see Appendix for notation) $u=\sqrt{\tau_{0} / \rho}=U_{\delta}{ }^{\frac{1}{2}}\left(\nu_{\pi} / T\right)^{\frac{1}{4}}$

$\mathrm{U}_{\delta}$ is the amplitude wave bottom velocity $\mathrm{U}_{\delta}=\pi \mathrm{T} / \mathrm{sinh} \mathrm{kd}$

For $R_{\delta}>160$, the boundary layer flow is turbulent, then the turbulent bottom shear $\tau_{0}=\rho f U_{\delta}^{2} / 8$ where $f$ is the Darcy-Weisbach friction factor, and $u_{*}=\sqrt{\frac{f}{8}} U_{\delta}$

2) The hydraulic properties of a sediment particle are often represented by its fall velocity $w$ in the water, defined by the equation

$$
133 \frac{\mathrm{gD}}{\mathrm{w}^{2}} \gamma^{\prime}=\mathrm{f}\left(\frac{\mathrm{wD}}{\nu}\right) \text { or } \frac{\mathrm{w}}{\sqrt{\gamma^{\prime} \mathrm{gD}}}=\mathrm{f}\left(\sqrt{\gamma^{\prime} \mathrm{gD}} \mathrm{D} / \nu\right)
$$

In Stokes range, $w D / v<0 \quad 1$

$$
\frac{w}{\sqrt{Y^{\prime} g D}}=\frac{1}{18}\left(\sqrt{\gamma^{\prime} g D} \mathrm{D} / \nu\right)
$$

3) In coastal processes, the sediment motion is caused by wave and tidal current actions In studying such interactions, an important criterion is the critical condition initiation of sediment motion Shields'criterion of the initiation of sediment motion is in the case of a steady current.

$$
\frac{T_{C}}{o g \gamma^{\top} D}=f_{1}\left(R_{{ }^{\prime} C}\right) \text { where } \tau_{C} \text { is the critical shear stress }
$$

$\mathrm{R}_{{ }_{x \mathrm{C}}}=\mathrm{u}_{\varkappa \mathrm{C}} \mathrm{D} / \nu$ is the critical boundary layer Reynolds number based upon grain diameter $D$ 
$u_{*}=\sqrt{T_{C} / \rho}$ is the critical shear velocity If a boundary layer densimetric Froude number $F_{*}$ is defined as $F_{*}=\frac{u_{*}}{\sqrt{g Y^{1} \bar{D}}}$ then Equation (6) can be expressed as $F_{{ }_{x}}=f\left(R_{{ }^{*}}\right)$ where $F_{\ddot{ }} C_{1}$ is the critical boundary layer Froude number For a given size of sediment, a critical velocity ${ }_{C}$ can easily be derived by noting the relation $u=C_{c} u_{y} / \sqrt{g}$ where $C_{c}$ is the Chezy coefficient (9)

Such criterion has also been investigated extensively in the case of sediments under wave action It is remarkable that the criterion is identical with that of the steady current case, although the range of $R * C 1 s$ considerably smaller For initiation of sediment motion due to wave action, the boundary layer Reynolds number $R_{*}$ based on grain diameter is given by

$$
R_{*}=21 \mathrm{D}\left(\frac{\mathrm{H}^{2}}{v^{3} \mathrm{~T}^{3} \sinh ^{2} \mathrm{kd}}\right)^{\frac{1}{4}} \mathrm{C}_{1 \mathrm{n} \text { a laminar boundary layer }}
$$

At present (1970) there is no experimental information on initiation of sediment motion due to combined wave and current actions known to the duthors Based upon dimensional consideration of similar nature as Equation (8), the criterion can be expressed as

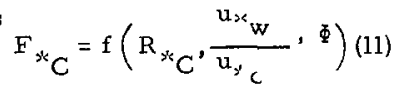

where $F_{* C}$ and $R_{* C}$ are critical boundary layer Froude and Reynolds numbers, based upon either wave or current shear velocities $1 \mathrm{e}$, $u_{* w}$ or $u_{\nu_{c}}$ respectively The parameter $u_{*} / u_{*_{c}}$ shear velocity ratio represents the relative importance of wave and current effects An additional factor is the angle of wave incidence to the current direction $\Phi$

4) The volume transport rate of bed load qs can be expressed in general as a function of boundary layer Reynolds number, $R_{*}$, boundary layer Froude number $F_{*}$ and sediment size distribution

$$
\begin{aligned}
& \frac{\mathrm{q}_{\mathrm{S}}}{\mathrm{u}_{\varkappa} \mathrm{D}}=\mathrm{f}_{1}\left(\mathrm{R}_{\varkappa}, \mathrm{F}_{\psi}, \sigma_{\mathrm{D}}\right) \\
& \frac{\mathrm{q}_{\mathrm{s}}}{\mathrm{u}_{,}\left(\mathrm{u}_{* *}^{2} / \mathrm{g}\right)}=\mathrm{f}_{2} \quad\left(\mathrm{R}, \mathrm{F}_{*,}, \sigma_{\mathrm{D}}\right)
\end{aligned}
$$

where $q_{5}$ is the volume sediment transport rate per unit width The effect of distribution of the sediment size is considered by including the geometric standard deviation $\sigma_{D}$

Sediment transport by waves is mainly due to mass transport and longshore currents On a beach, the onshore and off shore transport of sediments are reflected by the beach profiles The alongshore transport of sediment ( $\mathrm{e}$, littoral drift) is induced by longshore currents

For bed load transport due to combined wave and current action, the volume rate is expected to be affected by two additional parameters, 
namely, 1) the ratio of characteristic velocities between current and wave $u_{c} / u_{w}$, and 2) the incident angle of wave to the current direction $\Phi, 1 \mathrm{e}$,

$$
\frac{q_{s}}{u_{{ }_{n}}\left(u_{s}^{2} / g\right)}=f\left(R_{,}, F, u_{c} / u_{w}, \Phi, \sigma_{D}\right)
$$

5) Beaches are formed by wave and coastal sediment interactions Beaches are said to be in equilibrium when they reach stable profiles under relatively constant wave action This means that the offshore and onshore transport of sediments are in balance In general, the form of equilibrium profile of a beach depends upon the wave characteristics, such as wave height and wave length or wave steepness, sediment specific weight and sizes

There is no well established law on beach equilibrium which can be applied both to offshore and surf zones, or to both natural sand and scale model light material A study is now being conducted at Tetra Tech for this purpose

6) The most commonly accepted relation for littoral drift is approximately

$$
\frac{\gamma_{f} E}{2 g\left(\gamma_{s}-\gamma_{f}\right) D}=K \Omega_{s}\left(\frac{\gamma_{s}-\gamma_{f}}{\gamma_{f}}\right)^{1 / 2}\left(\frac{1}{g D^{3}}\right)^{1 / 2}
$$

where $E$ is the longshore energy and $K$ a constant coefficient (Manohar, 1962)

\section{SIMILITUDE RELATIONS FOR MOVAB LE BED RIVER MODELS}

The similitude relations for movable bed river models are derived based upon similitudes on (Boucher and Le Mehauté, 1957) l) basic flow characteristics and flow patterns, 2) head loss, 3) sediment transport characteristics and 4) kinematic condition on sediment motion

As in a coastal model, there are four basic scale ratios to be determined namely, $\lambda$, the horizontal scale $\mu$, the vertical scale (or distortion, $\Omega$ ), $D$, artificial sediment size, \& $\gamma^{\prime}$ apparent specific weight However, in many river model studies, an extra distortion is allowed for the river slope Here, only the case with one distortion is discussed

For similitude on basic flow characteristics and flow patterns, the model flow conditions are deduced based upon the Froudian law The scale ratio of flow velocity $n_{u}$ is $n_{u}=\mu^{\frac{1}{2}}$ and the time scale $n_{t}{ }^{1 s} n_{t}=\lambda_{\mu}{ }^{-\frac{1}{2}}$

For similitude of head loss, there are two conditions 1) the energy gradient, and 2) the bed configuration Based upon Chezy's formula

$\mathrm{u}=\mathrm{C}_{\mathrm{c}} \sqrt{\mathrm{dS} \mathrm{e}}$ where $\mathrm{C}_{\mathrm{c}}$ is the Chezy coefficient $=\sqrt{8 / \mathrm{f}}$

$d$ is the water depth $\simeq R_{h}$, the hydraulic radius for wide rivers $S_{e}$ is the energy gradient

Since the energy gradient for a distorted model must be exaggerated by a factor of $\Omega$, the scale ratio for the Chezy coefficient ${ }^{n_{C}}{ }_{c}{ }^{i s}{ }^{n} C_{c}=\Omega^{-\frac{1}{2}}$
and $n_{f}=\Omega$ 
This condition is valid for movable bed models as well as for fixed bed models (For the latter, the head loss is set up experimentally without taking into account the relative roughness ) For movable bed models, since the flow is kept fully turbulent, $C_{c}$ can be expressed as $C_{c}=K(d / D) 1 / 6$

where $K$ is a proportionality constant, and $D$ is the sediment size

A necessary condition for this Equation for $C_{c}$ to be applicable is that there should be no ripples or dune formation in the model This condition is $\mathrm{R}_{*}=\frac{\mathrm{u}_{*} \mathrm{D}}{\nu}=116 \frac{\mathrm{D}}{\delta_{\mathrm{v}}}>500$ (in the model), where $\mathrm{R}_{*}$ is a boundary layer

Reynolds number, $u_{2}=\sqrt{g_{d S}}$ is the shear velocity The condition $R_{*}>500$ implies $R>500$ where $R=\underline{u R_{h}}$ (i e , the flow is fully turbulent in the

model) Then the scale ratio for the sediment size ${ }^{n_{D}}$ is given by ${ }^{n} D=\mu \Omega^{3}$

For the similitudes of sediment transport characteristics, there are three basic aspects namely, 1) initiation of sediment motion, 2) regimes of bed configuration and 3) bed load sediment transport characteristics So far, modeling of the suspension transport has not been carried out

The condition of initiation of sediment motion due to current action, as discussed in a previous section, is $F_{{ }^{\prime} C}=f\left(R_{{ }^{\circ} C}\right)$, where $F_{C}$ is the critical boundary layer Froude number, and $R^{\prime} C$ is the critical boundary
layer Reynolds number

Based upon the general formula for bed load transport rate per unit width, $\mathrm{q}_{\mathrm{s}}$ can also be expressed in general functional relationship as

$$
\frac{q_{s}}{u_{*}\left(u_{*}^{2} / g\right)}=f_{2}\left(R_{*}, F_{v}, \sigma_{D}\right)
$$

Based upon the above reasoning the similitudes of sediment transports including condition of initiation of sediment motion, require $n_{F}=1$

$\mathrm{n}_{\mathrm{R}_{*}}=1 \quad$ (26) and $\mathrm{n}_{\sigma_{\mathrm{D}}}=1$

These Equations are entirely similar to those derived for coastal models

They imply $n_{u_{* x}}^{2} n_{\gamma^{\prime}}^{-1} n_{D}^{-1}=1$ and $n_{u_{v}}=n_{U_{\delta}}\left(n_{f}\right)^{\frac{1}{2}}=\mu^{\frac{1}{2}}\left(\frac{\mu}{\lambda}\right)^{\frac{1}{2}}$

or

$$
\mathrm{n}_{\gamma}, \mathrm{n}_{\mathrm{D}}=\mu \Omega
$$

In general, $R_{, t}$ in the field is large For large $R_{*}$, the sediment transport characteristics are approximately independent of $R_{*}$ On the other hand, it is desirable to prevent occurrence of ripples in the model Thus, Equation $n_{R_{y}}=1$ is relaxed in practice except specifying $R_{*}>500$ in the model At lar'ge $\mathrm{R} *$, the sediment transport characteristic $s$ are believed to be dependent primarily on $F_{x}$ On the model bed, it is undesirable to have extensive ripple formation $s$ because the model ripples often contribute too much flow resistance in comparison with the prototype condition and their effect is difficult to control

A kinematic condition of sediment motion is specified here as an additional basic similitude relation, a sediment in suspension travels distances in the 
vertical and the horizontal directions proportional to its fall velocity $w$ and its horizontal velocity $u, l_{1}$ e $x / y=u / w$, where $x$ and $y$ are horizontal and vertical distances of travel This Equation gives an additional condition on the basic unknowns

$$
\Omega=n_{w} / n_{u}=n_{w} \mu^{-\frac{1}{2}}
$$

Considering the value of the fall velocity $w$, the scale ratio $n_{w}$ is then given by $n_{w}=\left(n_{Y^{\prime}} n_{D} / n_{f w}\right)^{\frac{1}{2}}$, where $n_{f w}$ is the scale ratio of the function $f_{w}(w D / \nu)$ This condition cannot be expressed explicitly, because of the inclusion of $n_{f w}$ However, it is interesting to note that if one uses the same sediment in the model as in the prototype, $n_{w}=1$, the above Equation reduces to $\lambda^{2}=\mu^{3}$, which matches the Lacey relation (33) based on river statistics, but $n_{F_{*}}=1$ and $n_{R_{\psi}}=1$ are then not verified

In summary, the similitude relationships of movable bed river scale models are determined from three conditions 1) similarity of head loss $n_{f}=\mu / \lambda$, 2) similarity of sediment transport characteristics $n_{F}=1$ and 3 ) kinematic condition of sediment motion $n_{u}=\lambda$ leading to $F_{x}$ a well defined distortion In addition, there $\quad \frac{u}{n_{w}}=\frac{\lambda}{\mu}$ should be no ripple formation in the model $R_{*}>500$

The bed load transport formula, Equation (24) is used to obtain the time scale of bed evolution $n_{t b} n_{t b}=\lambda \mu / n_{q s}=\lambda^{5 / 2} \mu^{-2}$

The kinematic conditions imply Lacey's law at $n_{1}=1$ The Lacey's law is also compatible with the regime theory of rivers based upon statistical analyses of meandering rivers width $\propto \mathrm{Q}^{\frac{1}{2}}$, depth $\propto \mathrm{Q}^{1 / 3}$ In scale relations, it gives Identical relations as the one obtained by previous considerations, $1 \mathrm{e}$. $\lambda^{2}=\mu^{3}$

which is often used as a guide in choosing $\lambda$ and $\mu$ values However, since this is derived by assuming identical model and prototype sediments, another relationship should be used in actual choice of scale ratios This relationship can easily be verified quantitatively from the previous set of Equations where the particle fall velocity for the light scale model material is taken into account exactly

\section{SIMILITUDE OF SEDIMENT MOTION FOR COASTAL MODELS}

Similitude of sediment motion means homogeneous scaling of sediment transport characteristics in the model, $1 \mathrm{e}$, consistent quantitative relationships between the model and prototype transport quantities For a distorted Froudian model, similitude of wave refraction insures 
approximately identical $\mathrm{u}_{\mathrm{c}} / \mathrm{u}_{\mathrm{w}}$ and $\Phi$ values as in the prototype For constant $q_{s} / u_{\bullet}\left(\frac{u_{x}{ }^{2}}{g}\right)$, it requires

$$
\mathrm{n}_{F_{\%}}=1 \quad \mathrm{n}_{\mathrm{R}_{*}}=1 \quad \text { (36) (37) and } \mathrm{n}_{\sigma_{\mathrm{D}}}=1
$$

(The condition ${ }^{n_{\sigma_{D}}}=1$ is disregarded by most investigators ) These Equations give $\quad n_{u_{*}}^{2}=n_{Y^{\prime}} n_{D}$ and $n_{u_{*}} n_{D}=1$

The scale for $n$ is actually difficult to define, since the boundary layer characteristics vary ${ }^{\text {w }}$ from off shore (viscous case or ripples) to the breaking zone, where it is fully turbulent, without ripples

In the first case (viscous) $\quad \mathrm{n}_{\mathrm{u}_{*}}=\mu 1 / 8$

In the breaking zone

$$
\mathrm{n}_{\mathbf{u}_{x c}}^{\mathrm{u}_{\%}}=\mathrm{n}_{\mathrm{f}}{ }^{1 / 2} \mu^{1 / 2}
$$

Considering the state of the art, it is difficult to assess the value of $n_{f}$ If one assumes that $f$ in the surf zone is a function of the relative roughness, as in the case of a river, then $n_{f}=\mu / \lambda$ Then $n_{u_{*}} \cong \mu \lambda^{-\frac{1}{2}}$

$$
\mathrm{n}_{\mathrm{D}}=\lambda^{\frac{1}{2}} \mu^{-1}
$$

$$
n_{\gamma^{\prime}}=n_{D}-3=\mu^{3} \lambda^{-3 / 2}
$$

The use of natural sand, $n_{\gamma^{\prime}}=1$, would require that $n_{D}=1$ This implies that model sand should be identical to the prototype sand In this case, Equation (40) gives $\lambda^{\frac{1}{2}}=\mu$, which could be considered as the natural distortion law equivalent to Iacey condition $\lambda^{2}=\mu^{3}$ for rivers Since the scale for the slope is equal to distortion $n_{s}=\frac{\mu}{\lambda}, n_{s}=\frac{1}{\lambda^{\frac{1}{2}}} \quad$ (A natural beach subjected to 10 foot, 12 second waves of slope $\frac{1}{50}$ will ${ }^{\lambda^{\frac{1}{2}}}$ have a $\frac{1}{100}$ scale model slope of $1 / 5$ when subjected to a 1 foot, 4 second wave ) However, a lighter material than sand will actually insure less distortion and a more gentle scale model slope, therefore, less scale effects It is interesting to note that Equation $\lambda \frac{1}{2}=\mu$ is compatible with $n_{F_{*}}=1$ and also $n_{R_{*}}=1$ Consequently, sand can be theoretically used on scale models of beaches

Although similitude of $R_{*}$ and $F_{*}$ are obtained based upon the bed load transport formula, the similitude relationships have the following additional implications 1) similitude of initiation of sediment motion, and 2) similitude of regimes of sediment motion

Thus, such similitude relationships imply a similar and homogeneous transport characteristic over the model as in the prototype However, there are several restrictions before the above equations for $n_{D}$ and $n_{\gamma^{\prime}}$ can be used These limitations are

1) Both the prototype and the model boundary layers are turbulent (this is certainly true in the surf zone)

2) The model friction factor is scaled according to distortion of $n_{f}=\frac{\mu}{\lambda}$ model and prototype 
4) Moreover, the analysis here does not apply in the case of a pebble beach In such case, the condition of $\mathrm{n}_{\mathrm{R}_{*}}=1$ is replaced by a limiting value of
$\mathrm{R}_{*}$, say, of 500

Theoretically, relationships between scales, distortion, artificial sediments, etc, are obtained based upon similitude of sediment transport characteristics and equilibrium beach profiles Because of the uncertainties involved, certain prelıminary wave tank experiments are necessary The purpose of such wave tank experiments is to confirm the cholce of distortion and artificial sediments The similitude of sediment transport characteristics by selecting $n_{R}=1$ and $n_{F_{*}}=1$ gives not only the correct scaling of bed load transport, $R_{\rtimes}$ but afso the critical condition of sediment motion

The condition $n_{R}=1$ may then be too stringent and be replaced by a condition such as $R_{*}>R_{x<*}$, where $R_{s}$, is a minimum critical value for the scale model (say 160 implyıng a turbulent boundary layer)

An important scale ratio is the time scale of bottom evolution $n_{t b}$ The value of $\mathrm{n}_{\mathrm{tb}}$ is usually determined in the process of reproduction of bottom evolution Analytically, $n_{t b}$ can be obtained from any sediment transport formula (15) For a coastal movable bed model, the littoral transport formula, is proposed here to be used for determining the value of $n_{t b}$

$$
n_{t b}=\frac{\lambda^{2} \mu}{n_{Q s}}=\lambda^{2} \mu^{-3 / 2} n_{D}^{-1} n_{Y^{\prime}}^{\frac{1}{2}} \text { where } n_{Q s} \text { is the scale ratio of }
$$

the littoral transport rate This Equation is applicable only in the case of coastal problems where the littoral transport is the dominant sediment transport mechanism. For river models, a different formula has already been proposed This formula is useful in predicting time scale of bed evolution in the model At present, there are, to ou $r$ knowledge, two sets of data available for comparison

1) Cobourg Harbor Study (Le Méhaute and Collıns, 1961)

Model conditions $\lambda=1 / 200, \mu=1 / 60$ Artificial sediment Gilsonite, $\mathrm{n}_{\gamma}{ }^{\prime}=00182, \mathrm{n}_{\mathrm{D}}=7$.

Timescale by model reproduction of bottom evolution $n_{t b}=25 \mathrm{~min} \quad 1 \mathrm{yr}$

Timescale from proposed Equation $\mathbf{n}_{t b}=117$ minutes 1 year

In this study, the model wave helght was exaggerated, approximately, by a factor of two A correction of the wave height scaling based upon the littoral drift equation gives $\mathrm{n}_{\mathrm{tb}}=29$ minutes 1 year, which is close to the predicted value

2) Absecon Inlet Study (U $S$ Waterways Experiment Station, 1943)

Model conditions $\lambda=1 / 500, \mu=1 / 100$ Artificial sediment Sand, $\mathrm{n}_{\gamma^{\prime}}=1, \mathrm{n}_{\mathrm{D}}=063$

Timescale by model reproduction of bottom evolution $\mathrm{n}_{\mathrm{tb}}=13 \mathrm{hrs} 1 \mathrm{yr}$

Timescale from proposed Equation $n_{t b}=56$ hours 1 year

Again there is a correction on the exaggeration of the model wave heights (a factor of about two) $n_{t b}=14$ hours 1 year 
An additional correction is to be made due to the fact that 22 percent of time was not reproduced in the model when there was no littoral transport in the field $\mathrm{n}_{\mathrm{tb}}=11$ hours 1 year

Thus, these predicted time scales compared favorably with observed values The accuracy is estimated to be within 30 percent

\section{CONCLUSION}

The success of a movable bed scale model depends upon the proper choice of distortion and material Distortion is a natural observed phenomena, which needs to be strictly adhered to for similitude Its choice can theoretically be justified in the case of a river, based on well defined conditions of similitude These conditions lead to a Lacey type relationship close to $\lambda^{2} \cong \mu^{3}$ The law $\lambda^{2}=\mu^{3}$ prevalls in the case where the same material (sand) is used in both the prototype and the model This is the law of "natural distortion" which is not compatible with other conditions of similitude $\left(n_{F}=1, n_{f}=\Omega\right)$

The choice of scales and material is less well defined in the case of beaches However, for a given material and vertical scale, there is also a well defined rate of distortion based on the equilibrium profile of beaches This approach compensates to a large extent for the lack of understanding of the law of sediment transport by wave action If one assumes that the regime in the boundary layer is turbulent, the friction coefficient can be related to relative roughness (as in the case of a steady flow) and the same material, a law of "natural distortion" is also obtained such as $\lambda^{1 / 2}=\mu$ The first law is approximately verified by compilation of river statistics, while the second law $\left(\lambda^{1 / 2}=\mu\right)$ is obtained from theoretical considerations This law still needs to be proven, improved, or disproven from observation For the time being, one can only insure that it gives a qualitatively observed trend (Wiegel, 1964) Iighter scale model material will insure a smaller rate of distortion Therefore, the use of sand in movable scale models may provide too large a scale effect, even though it is now compatible with $n_{F *}=1$ and $n_{R}=1$ It is hoped that present studies on equilibrium profiles of beaches will solve some of the uncertainties that have been brought out in this paper In the meantime, pre$11 \mathrm{minary} 2 \mathrm{D}$ tests a re still necessary for determining distortion prior to designing any large $3 \mathrm{D}$ model

It 1 s also hoped that the present paper will help to demonstrate that movable bed scale model technology is not "magic witchcraft" after all

\section{ACKNOW LEDGMENTS}

This study was sponsored by the Coastal Engineering Research Center, Washington, D C , under Contract DAC W 72-68-C-0020 The writer is indebted to Drs 1 Collins, E Noda, and L N Fan for many fruitful discussions 


\section{SUMMAR Y}

Conditions of Similitude

\begin{tabular}{|c|c|}
\hline Coastal & Fluvial \\
\hline $\begin{array}{l}\text { 1) Similitude of wave refraction } \\
\text { Time scale } n_{t}=\mu^{\frac{1}{2}} \\
\text { Velocity, current } n_{u} \cong \mu^{\frac{1}{2}} \\
\text { Similitude of wave breaking } \\
n_{H_{b}}=\mu\end{array}$ & $\begin{array}{l}\text { 1) Normal Froude similitude for dis- } \\
\text { torted model } \\
\text { Time scale } n_{t}=\lambda / \mu^{\frac{1}{2}} \\
\text { Velocity } \quad n_{u}=\mu^{\frac{1}{2}}\end{array}$ \\
\hline 2) $n_{F_{*}}=1 \quad n_{u_{*}}^{2}=n_{Y^{\prime}} n_{D}$ (imperative) & 2) $n_{F_{x}}=1 \quad n_{u_{y}}^{2}=n_{\gamma^{\prime}} n_{D}$ (imperative) \\
\hline 3) $n_{R_{*}}=1 \quad \begin{array}{l}\text { (not imperative, } \\
\text { but recommended) }\end{array}$ & 3) $R_{x, 5}>500$ no ripple (imperative) \\
\hline $\begin{array}{l}\text { 4) Short model independent of } \\
\text { relative roughness } \\
\mathrm{n}_{\mathrm{u}_{\nu}} \cong \mu \lambda^{-\frac{1}{2}} \text { if }(?) \mathrm{n}_{\mathrm{f}}=\mu / \lambda \text { (surf zone) }\end{array}$ & 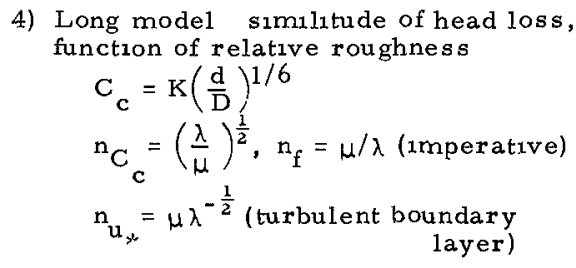 \\
\hline $\begin{array}{l}\text { 5) Suspension } \\
\qquad \frac{n_{u}}{n_{w}}=\frac{\lambda}{\mu} \text { (not imperative?) }\end{array}$ & $\begin{array}{l}\text { 5) Suspension } \\
\qquad \frac{n_{u}}{n_{w}}=\frac{\lambda}{\mu}\end{array}$ \\
\hline $\begin{array}{l}\text { 6) Distortion imposed by equilibrium } \\
\text { profiles of beaches (Still undeter- } \\
\text { mined for light model material) }\end{array}$ & $\begin{array}{l}\text { 6) } 2,4 \text {, \& } 5 \text { combined lead to a dis- } \\
\text { tortion with different material (1mper- } \\
\text { ative) }\end{array}$ \\
\hline $\begin{array}{l}\text { Natural distortion (same material), } \\
\text { and where } \\
\qquad \mathrm{n}_{\mathrm{f}}=\frac{\mu}{\lambda} \lambda^{\frac{1}{2}}=\mu \\
\quad \text { Compatible with } \mathrm{n}_{F_{*}^{*}}=1, \mathrm{n}_{\mathrm{R}_{\text {, }}}=1 \\
\text { but too large distortion(scale effects) }\end{array}$ & $\begin{array}{l}\text { Natural distortion (same material) } \\
\lambda^{2}=\mu^{3} \\
\text { Compatible with "regime theory", but } \\
\text { not with } n_{F,}=1\end{array}$ \\
\hline
\end{tabular}




\begin{tabular}{|c|c|c|c|}
\hline \multirow{2}{*}{\multicolumn{2}{|c|}{$\begin{array}{l}\text { Phenomena and } \\
\text { Important Quantities }\end{array}$}} & \multicolumn{2}{|c|}{ Simulitude Relations } \\
\hline & & Fluvial & Coastal \\
\hline A) & $\begin{array}{l}\text { Geometry } \\
\text { Horizontal length } \\
\text { Vertical length } \\
\text { Distortion } \Omega \\
\text { Slope (river, beaches) S }\end{array}$ & $\begin{array}{c}\lambda \\
\mu / \lambda \\
\mu / \lambda\end{array}$ & $\begin{array}{l}\lambda \\
\mu \\
\mu / \lambda \\
\mu / \lambda\end{array}$ \\
\hline B) & $\begin{array}{l}\text { Water Motion Characteristics } \\
\text { Water depth d, wave breaking depth } \mathrm{d}_{\mathrm{b}} \\
\text { Wave height } \mathrm{H} \text {, breaking wave hgt } \mathrm{H}_{\mathrm{b}} \\
\text { Wave length } \mathrm{L} \\
\text { Wave period } \mathrm{T} \\
\text { Refraction angle \& wave breaking angle } \\
\text { Wave diffraction, reflection } \\
\text { Time scale t } \\
\text { Particle velocity } \\
\text { Mass transport longshore velocity } \\
\text { Friction coefficient } \mathrm{f} \\
\text { Chezy coefficient } \mathrm{C} c \\
\text { Viscous sublayer } \\
\text { Shear velocity } \mathrm{u}_{,} \\
\text {Energy slope } \\
\text { Head loss }\end{array}$ & $\begin{array}{l}\mu \\
\\
\lambda / \mu^{\frac{1}{2}} \\
\mu \frac{1}{2} \\
\Omega \Omega \frac{1}{2} \\
\Omega^{-\frac{1}{2}} \\
(\mu \Omega)^{-\frac{1}{2}} \\
(\mu \Omega)^{\frac{1}{2}} \\
\\
\Omega \\
\mu\end{array}$ & 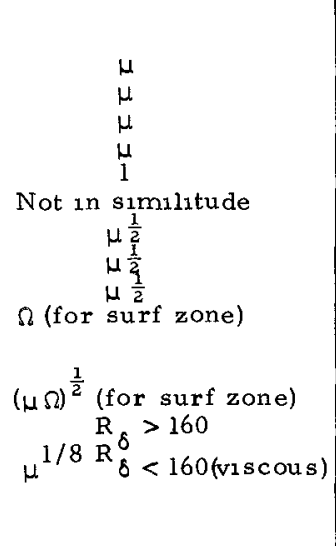 \\
\hline C) & $\begin{array}{l}\text { Sediment Characteristics } \\
\text { Sediment size D } \\
\text { Apparent specific weight } \gamma^{\prime} \\
\text { Size distribution } \sigma_{D}\end{array}$ & $\begin{array}{l}\lambda_{3}^{\frac{1}{2}} \mu^{-1} \\
\mu^{-3 / 2} \\
1\end{array}$ & $\lambda_{3}^{\frac{1}{2}} \mu^{-1}($ for surf zone $)$ \\
\hline D) & $\begin{array}{l}\text { Initiation of Motion } \\
\text { Critical boundary layer } \\
\text { Reynolds number } R_{4} \\
\text { Critical boundary layer } \\
\text { Froude number } F_{3 \times}\end{array}$ & $\begin{array}{c}R_{2 x}>500 \\
1\end{array}$ & 1 \\
\hline E) & $\begin{array}{l}\text { Sediment Transport Characteristics } \\
\text { Boundary ldyer Reynolds number } R_{*} \\
\text { Boundary ldyer Froude number } F_{*} \\
\text { Volume of deposition or erosion } \\
\text { Time of bed evolution }\end{array}$ & $\begin{array}{l}>500 \\
\lambda^{1} \lambda^{2 / 2} \mu \\
\mu-2\end{array}$ & $\begin{array}{l}1 \text { or } n_{u_{*}} n_{D}=1 \\
1 \text { or } n_{u}^{2}=n \gamma^{\prime} n_{D} \\
\lambda^{2} \mu \\
\lambda^{2} \mu^{-3 / 2} n_{D}-1 n_{\gamma^{\prime}} \frac{1}{2}\end{array}$ \\
\hline
\end{tabular}


Comparisón of Various Approaches for Determination of Basic Scale Ratios of A Coastal Movable Bed Model

\begin{tabular}{|c|c|c|}
\hline Authors & Basic Relations & Method of Derivation \\
\hline $\begin{array}{c}\text { Goddet \& Jaffry } \\
(1960)\end{array}$ & $\begin{array}{l}n_{D}=\mu{ }^{17 / 20} 8 / 5 \\
n_{\gamma^{\prime}}=\mu^{3 / 20} \Omega^{-3 / 5}\end{array}$ & $\begin{array}{l}\text { Sediment motion due to } \\
\text { combined action of waves } \\
\text { and currents }\end{array}$ \\
\hline $\begin{array}{l}\text { Valembo1s } \\
(1960)\end{array}$ & $\begin{array}{l}\Omega=n_{\gamma^{\prime}}^{-1} \\
n_{\gamma^{\prime}} n_{D}^{3}=1 \\
\mu=n_{\gamma^{\prime}}^{3} n_{D}\left(n_{H} / \mu\right)^{-4}\end{array}$ & $\begin{array}{l}\text { Kinematics of motion of } \\
\text { suspended sediments } \\
\text { Similitude of D } \\
\text { Modified relation of initia- } \\
\text { tion of sediment motion } \\
D \quad=K R, 8 / 9\end{array}$ \\
\hline Yalin (1963) & $\begin{array}{l}\mathrm{n}_{\mathrm{D}}=\mu^{3 / 4} \lambda^{1 / 2} \\
\mathrm{n}_{\gamma^{\prime}} \mathrm{n}^{3}=1\end{array}$ & Dimensional analysis \\
\hline Bijker (1967) & $\begin{array}{l}n_{\gamma^{\prime}} n_{D} \Omega^{-1}=\mu n \\
\Omega \leftarrow \text { equilibrium beach profiles }\end{array}$ & Similitude of $F_{2}$ \\
\hline $\begin{array}{l}\text { Present } \\
\quad \text { Method(1970) }\end{array}$ & $\begin{array}{c}n_{\gamma^{\prime}} n_{D}^{3}=1 \\
n_{\gamma^{\prime}}=\mu^{3} \lambda^{-3 / 2} \text { or } \\
{ }^{n_{D}}=\lambda^{1 / 2} \mu^{-1} \\
\Omega \text { equilibrium beach profiles }\end{array}$ & $\begin{array}{l}\text { Similitude of sediment } \\
\text { transport characteristics, } \\
1 \mathrm{e}, \mathrm{F} \text { and } \mathrm{R} \text {, }\end{array}$ \\
\hline
\end{tabular}




\section{LIST OF SYMBOLS}

$C_{c} \quad$ Chezy coefficient $\left(L^{\frac{1}{2}} T^{-1}\right)^{x}$

d depth of water

$d_{b} \quad$ depth of water at breaking

D mean sediment size

$D_{\%} \quad$ dimensionless sediment size $=\left(\frac{\left(\gamma_{s}-\gamma_{f}\right) g}{\nu^{2} \gamma_{f}}\right)^{1 / 3} D=\left(R_{,} / F\right)^{2 / 3}$

E wave energy flux per unit length of the crest $\left(\mathrm{MLT}^{-2}\right.$ )

f Darcy-Weisbach friction factor

$F_{*} \quad$ boundary layer densimetric Froude number $=u_{2 \xi} / \sqrt{\gamma^{\prime} g D}$

$F_{*} \quad$ critical boundary layer Froude number on initiation of sediment motion

g acceleration of gravity

$\mathrm{H}$ wave height

k wave number $=2 \pi / \mathrm{L}$

L wave length

$\mathrm{n}_{\text {quantity }}$ scale ratio with subscripts denoting corresponding quantities = (value of model)/(value of prototype) e $g, n_{L}$ is the scale ratio of the wave lengths

$q_{S} \quad$ volumetric sediment transport rate per unit width $\left(\mathrm{L}^{2} \mathrm{~T}^{-1}\right)$

$Q_{\mathrm{s}} \quad$ volumetric sediment transport rate $\left(\mathrm{L}^{3} \mathrm{~T}^{-1}\right)$

$r$ radial coordinate

$R_{h} \quad$ hydraulic radius

$R_{\delta} \quad$ boundary layer Reynolds number $=U_{\delta} \delta / \mathrm{V}$

$R_{\varkappa} \quad$ boundary layer Reynolds number based upon sediment size $=$ $u_{2 c} D / v$

$R_{x_{s}} \quad$ critical boundary layer Reynolds number on initiation of sediment motion

S slope

$S_{e} \quad$ energy gradient

t time

$t_{b} \quad t_{1}$ me of bed evolution

$\mathrm{T}$ wave period

u horizontal velocity

${ }^{u_{C}} \quad$ critical velocity for sediment motion 


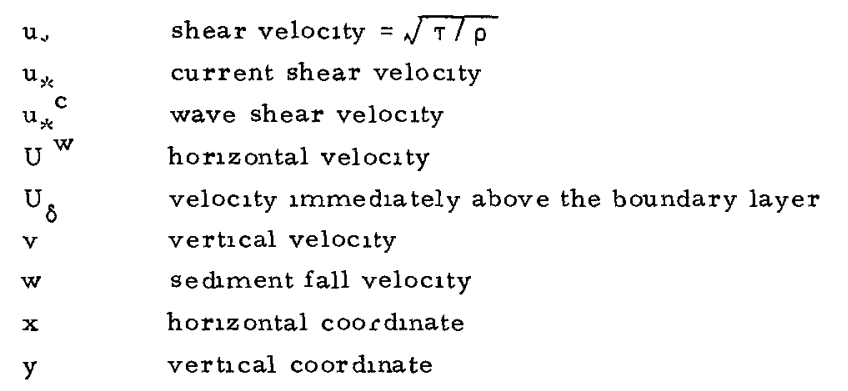

$\delta$ boundary layer thickness

${ }^{\delta} \mathrm{L} \quad$ laminar boundary layer thickness parameter turbulent boundary layer thickness

${ }^{T_{C}} \quad$ critical shear stress on the initiation of sediment motion 


\section{PARTIAL LIST OF REFERENCES}

Bascom, W N (1951), "The Relationship Between Sand Size and BeachFace Slope", Trans AGU, 32, No 6, December, pp 866-874

Bijker, E W (1967), "Some Considerations About Scales for Coastal Models with Movable Bed", Delft Hyd Lab, Pub No 50, Nov, 142 pages

Bonnefille, R, and Pernecker, L (1965), "Note de Synthese Sur Les Mouvements Des Fonds Marıns Sous LAction des Courants et de La Houle", National Hydraulics Lab, Chatou Res and Exp't Center, France 66 pages

Boucher, R, and Le Méhauté, B (1957), "L'etude Experimentale des Problemes de 1'Hydraulique Fluviale", L'ingenieur, Montreal, pp $49-58$

Collıns, J I (1963), 'Inception of Turbulence at the Bed Under Periodic Gravity Waves", J of Geophy, Res, Vol 68, No 21, Nov, pp $6007-6014$

Divoky, D, Le Mehaute, B, and Lin, A (1969), "Breaking Waves on Gentle Slopes", AGU

Eagleson, P S , Glenne, B , and Dracup, J A (1963), 'Equilibrium Characteristics of Sand Beaches", J of Hyd Div, Proc ASCE, Jan, pp 35-57

Fan, L N , and Le Mehauté, B (1969), "Coastal Movable Bed Scale Model Technology", Tetra Tech, Inc No TC-131

Goddet, J (1960), "The Intral Stages of the Transport of Materials Under Wave Action" La Houlle Blanche, No 2, March-April, pp 122135

Goddet, J, and Jaffry, P (1960), "Sımilitude Laws for Sediment Transport Under the Simultaneous Action of Waves and Currents", La Hourlle Blanche, No 2 March-Apr11, pp 136-147

Larras, J (1957), "Effet D'echelle Dans Les Etudes D'erosion du Sable Par La Houle Et Par Le Clapotis", Proc of 7 th Cong If IAHR, Lisbon, Paper No A-5 13 pages

Le Méhauté, B, and Brebner, A (1961), "An Introduction to Coastal Morphology and Littoral Processes", CE Dept, Res Rept 14, Queen's University, Jan, 46 pages

Le Mehauté, B , and Collıns, J I (1961), "A Model Investigation of Cobourg Harbor", CE Dept, Res Rept 17, Queen's University, July

Le Mehaute, B (1962), "Theory, Experiments, A Phılosophy of Hydraulics", J of Hyd Div, Vol 88, HY 1, Proc of ASCE, Jan pp $45-66$ 
Le Mehaute, B and Koh, R C Y (1967), "On the Breaking of Waves Arriving at an Angle to the Shore", J of Hydraulic Research, 5. No 1, pp 67-88

Manohar, M (1962), Discussion of "Laboratory Determination of Littoral Transport Rate", by $R$ P Savage, J of Waterways and Harbors Div, Proc ASCE, $\underline{88}$, No 4, Nov pp 144-147

Savage, R P (1962), "Laboratory Determination of Littoral Transpoxt Rates", Journal of Waterways and Harbors Div, Proc , ASCE, May, pp 69-92

Saville, T Jr (1950), "Model Study of Sand Transport Along an Infinitely Long, Straight Beach", Trans AGU, 31, No 4, Aug pp 555-565

Saville, T Jr (I957), "Scale Effects in Two-Dimensional Beach Studies", Paper No A-3, Proc of 7 th Congress of IAHR, Lisbon

Simmons, H B (1950), "Contribution of Hydraulic Models to Coastal Sedimentation Studies", Proc of lst Conf on Coastal Engrg, Long Beach, 19 pages

Simmons, H B (1966), "Tıdal and Salınity Model Practıce", Ch 18 of Estuary and Coastlıne Hydrodynamics", Ed by $A$ T Ippen, pp $711-731$

Sitarz, J A (1963), "Contribution a l'Etude de L'evolution des Plages a Partir de la Connaissance des Profils D'equilıbre"', Travaux du Center de Recherches et d'Etudes Oceanographiques, Vol 5, Sept

Valembois, J (1960), "Etude Sur Modele Du Transport Littoral Conditions De Similitude", Ch 18, Proc 7th Conf on Coastal Engrg, The Hague, pp 307-317 (English Translation, U S Army Corps of Engineers, Waterways Experiment Station, Translation No 65-7, July 1965)

Vanon1, V A Brooks, N H and Kennedy, J F (1961), "Lecture Notes on Sediment Transportation and Channel Stabılity", W M Keck Lab of Hydraulics and Water Resources, Tech Report KH-R-1, Callf Institute of Technology, Pasadena, California, Jan

Wiegel, R I (1964), "Oceanographical Engineerıng", Prentice-Hall, Inc , Englewood Cliffs, N J , 527 pages (p 359)

Yalin, S (1963), "Method for Selecting Scales for Models with Movable Bed Involving Wave Motion and Tidal Currents", Proc of 10 th Congr of IAHR, Vol 1 , paper I 30, London 